\title{
Reconfigurable control as actuator fault-tolerant control design for power oscillation damping
}

Digvijay V. Nair ${ }^{{ }^{*}}$ and MSR Murty ${ }^{2}$

\begin{abstract}
This paper presents design of an self contained actuators unit in wide area damping control of power system in stabilizing system response for both nominal system condition and during actuator faults. First it is presented that use of multiple actuators in wide area control aid in improving damping in power system. A wide area damping controller feeding multiple actuators to satisfy multiple objectives in wide area damping control of power system is designed. Minimization of infinity norm of closed loop transfer function of power system with wide area controller in feedback path \& closed loop poles placement techniques are used in controller synthesis. Second a reconfigurable control on the lines of fault hiding principle is added to the controller design to maintain system damping to pre-fault level in case of actuator faults. A reconfiguration component( $\mathrm{RC})$ is activated on occurrence of actuator fault thereby reconfiguring system dynamics and redistributing wide area control signal among remaining active actuators. RC together with remaining active actuators and under same wide area damping controller maintains system damping to pre-fault level thereby preserving system dynamic response. In the reconfigurable control design presented here no new actuators outside the unit of actuators designed for wide area damping control is required. This makes for an self contained actuators unit in wide area damping control of power system both for nominal system condition and for system affected by actuator faults. A two area power system model is considered here for demonstrating effectiveness of designed robust damping controller with multiple outputs feeding multiple actuators in wide area control and illustrating the idea of self contained actuators unit for maintaining system damping in case of actuator faults.
\end{abstract}

Keywords: Wide area control, Robust damping controller, Actuator fault, Reconfigurable control, Reconfiguration component, Self contained actuators unit, Power oscillations

\section{Introduction}

One of the major concerns of power system is small signal instability and power oscillations arising out of small changes taking place in power system. Small signal stability is the ability of the system to maintain synchronous operation of generators for constant changes(small in comparison to net generated power in system) in operating conditions of power system. This can be load changes, transmission line outages, generator faults and so on. These constant changes witnessed in power system results in power oscillations mostly of electro-mechanical in

${ }^{*}$ Correspondence: digvijay@ifheindia.org

${ }^{1}$ Faculty of Science \& Technology, IFHE HYDERABAD, Shankerpally Road, 501203 Hyderabad, India

Full list of author information is available at the end of the article nature involving multiple machines with-in same or different areas exchanging power between them [1]. Local oscillations are damped by control units like power system stabilizers(PSS) but for inter-area oscillations involving generators from different areas is difficult to be damped locally. Local controllers lack global observation to see inter-area modes responsible for power oscillations between machines from different areas [2]. With advent of phasor measurement units(PMUs) involved in synchronised and high speed data measurements and transmission from remote locations is made possible [3, 4]. This solves problem of lack of global observation needed for control action to damp out inter-area oscillations [5]. PMUs led to newer controller designs for wide area damping control of power system [6-8]. Dedicated controllers connecting remote signals to local stabilizing units are 
designed as part of wide area control(WAC) and damping of power system. Newer controller design techniques based on remote feedback signals and wide area control inputs capable of robust system performance under wide operating conditions have been made possible[7, 9].

The pace of implementation of wide area control \& damping in power system is slow. The reluctance of power companies to do so can be attributed to issues like latency in transmission of wide area signals, insufficient bandwidth \& loss of wide area signals [10]. The use of centralized controller in WAC of power system requires highly reliable communications and fast and efficient computations. Signals are transmitted from remote locations to central controller and from there to select reference inputs(actuators) of power system. Any delay in transmission and arrival of signal or loss of link between controller and power system can adversely affect system performance [11].

The development of WAC includes design of supplementary control inputs at excitation system of generators, at reference input of HVDC system \& at reference input of FACTS devices. The loss of either of (i) remote signals to controller called as sensor faults or (ii) control signals from controller to system termed as actuator faults, reduces effectiveness of WAC. To gain full benefit of WAC in oscillation damping and improving reliability of it's operation wide area controller should be cemented further with appropriate fault tolerant control strategy to prevent any deterioration from setting in system response. The issues of loss of remote signals in WAC and it's effect on system stability was studied and reported in $[11,12]$. Few fault tolerant control designs for damping of oscillations in $W A C$ of power system are [13-17]. Sevilla et al. [16] has dealt specifically with sensor faults in WAC and presented fault tolerant controller effective during fault but conservative in action during normal system condition. In [15] design of dynamical block called virtual actuator on occurrence of actuator fault as part of fault tolerant damping controller is presented. Pedersen et al. [13] presents design of $V A$ as part of fault tolerant emergency control for system stability under sudden loss of actuator in WAC of power system.

In this paper design of self contained actuators unit, a novel concept, in wide area damping control of power system, for maintaining sufficient damping in system under different operating points and at the same time capable of restoring system performance on actuator fault is presented. First the use of multiple actuators in wide area damping control and its effectiveness in increasing damping in system is presented. A wide area robust damping controller(WRDC) with multiple outputs connected to multiple actuators(here called self contained unit of actuators) is synthesized to meet multiple requirements from it like disturbance rejection, control effort optimization
\& to maintain minimum specified damping in system. The design framework used to realize WRDC is based on linear matrix inequality(LMI) condition. Each LMI corresponds to a constraint imposed on controller. Solving for optimization of defined objective function under given constraints results into controller realization.

Second a reconfigurable control is added to wide area damping controller that on actuator fault activates an dynamical block called reconfiguration component(RC). $\mathrm{RC}$ together with remaining active actuators(from the same unit) compensate for loss of control action due to actuator fault. RC redistributes wide area control signal to active actuators left from the unit without need of adding any redundant actuator to the unit. $\mathrm{RC}$ is designed to satisfy fault hiding principle that hides the actuator fault from the nominal WRDC. On activation of RC the same nominal WRDC is used in generating control action required for meeting specified minimum damping in system and maintaining system performance post actuator fault. The dependence on actuators from same unit designed for wide area control and damping of power system even in case of actuator faults for maintaining system performance makes for an self contained actuators unit. The unit consisting of multiple actuators involved in wide area damping control with controller(WRDC) becomes self sufficient and sees dynamic allocation of control action among active actuators on actuator faults during control operation. This paper extends $[18,19]$ from discussing effect of actuator faults on system performance to proposing FTC strategy against actuator fault. In particular this paper extends [15] from single actuator to multiple actuator based wide area control, proposing design of self contained actuators unit independently stabilizing system response on actuator fault without any dependence on redundant actuators unlike in [15].

The rest of the paper is organized as follows: dynamic model representation of components used as actuators in WAC is given in Section 2, in Section 3 robust control design of wide area robust damping controller(WRDC) is given. In Section 4 the proposed concept of self contained actuators unit in wide area control \& damping is described and design of reconfiguration component(RC) and its application to WAC of power system is given. In Section 5 study of proposed wide area robust damping controller(WRDC) and reconfigurable control as fault tolerant control methodology on a two area power system is presented with results and discussion. Concluding remarks are made in Section 6.

\section{Inputs:wide area control of power system}

In this section model representation of components used as possible inputs(actuators) in wide area control of power system is given. The supplementary control input at Generator's excitation system, FACTS devices like static var 
compensator(SVC) \& High voltage dc system(HVDC) can be used for connecting wide area damping controller to power system. Rotor dynamics of synchronous machine is described in (1) [20, 21].

$$
\begin{aligned}
\frac{d \delta}{d t} & =\omega-\omega_{0} \\
\frac{2 H}{\omega_{0}} \frac{d \omega}{d t}=T_{m}-D\left(\omega-\omega_{0}\right)-\left(\psi_{d} i_{q}-\psi_{q} i_{d}\right) & \frac{1}{\omega_{0}} \frac{d \psi_{f}}{d t}=V_{f}-r_{f} i_{f} \\
\frac{1}{\omega_{0}} \frac{d \psi_{k d}}{d t} & =-r_{k d} i_{k d} \\
\frac{1}{\omega_{0}} \frac{d \psi_{k q 1}}{d t} & =-r_{k q 1} i_{k q 1} \\
\frac{1}{\omega_{0}} \frac{d \psi_{k q 2}}{d t} & =-r_{k q 2} i_{k q 2}
\end{aligned}
$$

Where generator constants $r_{f}, r_{k d}, r_{k q 1} \& r_{k q 2}$ are given in (2). The variables and constants used in (1) \& (2) are described in nomenclature.

$$
\begin{array}{r}
r_{f}=x_{a d u s}^{2} /\left(x_{d}-x_{d}^{\prime}\right) / \omega_{0} T_{d 0}^{\prime} \\
r_{k d}=\left(x_{d}^{\prime}-x_{l}\right)^{2} /\left(x_{d}^{\prime}-x_{d}^{\prime \prime}\right) /\left(\omega_{0} T_{d 0}^{\prime \prime}\right) \\
r_{k q 1}=x_{a q u s}^{2} /\left(x_{q}-x_{q}^{\prime}\right) / \omega_{0} T_{q 0}^{\prime} \\
r_{k q 2}=\left(x_{q}^{\prime}-x_{l}\right)^{2} /\left(x_{q}^{\prime}-x_{l}\right)^{2} /\left(x_{q}^{\prime}-x_{q}^{\prime \prime \prime} / \omega_{0} T_{q 0}^{\prime \prime}\right.
\end{array}
$$

Generator is equipped with controls like (i) excitation system(ES) for maintaining constant terminal voltage and (ii) turbine-governor for constant rotor speed. The role of ES is primarily to regulate terminal voltage of generator under different changes in system. ES additionally provides damping component of torque for fast settling of response in attaining steady state condition. The wide area control signal is fed to the supplementary input terminal of ES as part of WAC to increase the damping in the system. The dynamics of ES is described by the (3) [22].

$$
\frac{d E_{f d}}{d t}=-\frac{E_{f d}}{T_{A}}+\frac{K_{A}}{T_{A}}\left[V_{r} e f+V_{p s s}-V+V_{m o d}^{e}\right]
$$

The $2^{\text {nd }}$ supplementary control input in WAC for damping of power oscillations is provided by static var compensator $(S V C)$. The main control objective of $S V C$ is to maintain constant bus voltage. It comprises of thyristor control rectifier(TCR) and fixed capacitor(C). Setting appropriate values of firing angle of TCR, net susceptance $\left(B_{s v c}\right)$ and reactive current by it can be controlled. The dynamic model of SVC used here is given in
(4) $[23,24]$. The variables and constants used in (4) are described in nomenclature.

$$
\begin{array}{r}
T_{3 s} \frac{d X_{1 s v c}}{d t}=-X_{1 s v c}+\frac{K_{s}\left(T_{3 s}-T_{1 s}\right)}{T_{3 s}}\left[V-V_{r e f}+V_{m o d}^{s}\right] \\
T_{4 s} \frac{d X_{2 s v c}}{d t}=\frac{K_{s}\left(T_{4 s}-T_{2 s}\right)}{T_{4 s}} X_{1 s v c}-X_{2 s v c}+\frac{K_{s} T_{1 s}\left(T_{4 s}-T_{2 s}\right.}{T_{3 s} T_{4 s}}\left[V-V_{r e f}+V_{m o d}^{s}\right] \\
T_{5 s} \frac{d B_{s v c}}{d t}=\frac{T_{2 s}}{T_{4 s}} X_{1 s v c}+\left(X_{2 s v c}-B_{s v c}\right)+\frac{k_{s} T_{1 s} T_{2 s}}{T_{3 s} T_{4 s}}\left[V-V_{r e f}+V_{m o d}^{s}\right]
\end{array}
$$

The supplementary control terminal at the input of the HVDC system serves as another possible input point location for wide area control signal. HVDC system is based on line commutated converter. Damping can be increased in power system by modulating the reference current at the input of the rectifier. The dynamics of the modulated DC power by applying wide area control input to the supplementary control terminal of HVDC system is as represented in (5) [15]. The variables and constants used in (5) are explained in nomenclature.

$$
T_{d c} \frac{d P_{d c}}{d t}=-P_{d c}+P_{r e f}+\operatorname{sat}\left(P_{s}^{H V D C}\right)
$$

\section{Wide area robust damping controller:WRDC}

In this section a wide area robust damping controller(WRDC) for damping of power oscillations is designed. The wide area controller is designed to meet multiple objectives from sensitivity minimization, to attenuate disturbance effects on system output to achieve desired minimum damping in system. The objective of sensitivity minimization in presence of system uncertainties and disturbance attenuation is obtained by minimizing the infinity norm of the closed loop transfer function between output disturbance $(\mathrm{d})$ and system input $(\mathrm{u})$ as shown in Fig. 1. The second objective of minimum damping in system is obtained by regional closed loop pole placement in conic region in complex plane.

The linear model of nominal system under normal operating conditions is given by (6). It is represented as open loop $\operatorname{system}(G)$ in the Fig. 1.

$$
\Sigma_{G}:\left\{\begin{array}{c}
\dot{\mathbf{x}}=\mathbf{A x}+\mathbf{B u}+B_{d} d \\
\mathbf{y}=\mathbf{C x}
\end{array}\right.
$$

where matrices A, B \& $\mathbf{C}$ are the state matrices of appropriate dimensions depending on system order and number of inputs and outputs. A dynamic controller $(K(s))$ representing WRDC is connected to open loop system $(G(s))$, representing power system. With select output signals of $G$ as feedback to $K$ and output of $K$ to select inputs of $G$ forms a closed loop system as shown in Fig. 1. The state space model of $K(s)$ is as given in (7).

$$
\Sigma_{K}:\left\{\begin{array}{c}
\dot{\mathbf{x}_{\mathbf{k}}}=A_{c} \mathbf{x}_{\mathbf{k}}+B_{c} \mathbf{y} \\
\mathbf{u}=C_{c} \mathbf{x}_{\mathbf{k}}
\end{array}\right.
$$




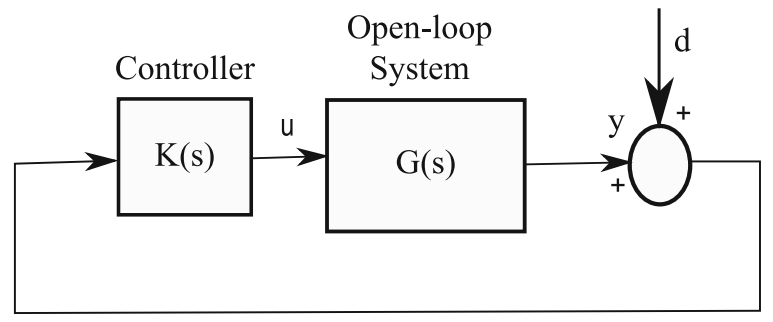

Fig. 1 Closed loop system with disturbance input

The infinity norm of closed loop transfer function from disturbance signal $\mathbf{d}$ to system input $\mathbf{u}$ is given by

$$
\begin{aligned}
& \left|\left[\mathbf{K}(\mathbf{I}-\mathbf{G K})^{-} \mathbf{1}\right]\right|_{\infty}<\gamma_{\mathbf{c}} \\
& {\left[\mathbf{K}(\mathbf{I}-\mathbf{G K})^{-\mathbf{1}}\right] \stackrel{\stackrel{s}{=}}{=}\left[\begin{array}{c|c}
\hat{\mathbf{A}} & \hat{\mathbf{B}} \\
\hline \hat{\mathbf{C}} & \mathbf{0}
\end{array}\right]}
\end{aligned}
$$

where closed loop state matrices $(\hat{\mathbf{A}}, \hat{\mathbf{B}}$ and $\hat{\mathbf{C}})$ are given by

$$
\begin{aligned}
& \hat{\mathbf{A}}=\left[\begin{array}{cc}
\mathbf{A} & \mathbf{B C}_{\mathbf{c}} \\
\mathbf{B}_{\mathbf{c}} \mathbf{C} & \mathbf{A}_{\mathbf{c}}
\end{array}\right] \\
& \hat{\mathbf{B}}=\left[\begin{array}{c}
\mathbf{0} \\
\mathbf{B}_{\mathbf{c}}
\end{array}\right] \\
& \hat{\mathbf{C}}=\left[\begin{array}{ll}
\mathbf{0} & \mathbf{C}_{\mathbf{c}}
\end{array}\right]
\end{aligned}
$$

Where the scalar $\gamma_{C}$ is any positive number $\left(\gamma_{C}>0\right)$. Minimization of the $\gamma_{C}$ results into disturbance rejection characteristic of the closed loop system. On applying positive real lemma to (8), matrix inequality condition of (11) is obtained $[16,25]$.

$$
\left[\begin{array}{ccc}
\hat{\mathbf{Q}} \hat{\mathbf{A}}+\hat{\mathbf{A}}^{\mathrm{T}} \hat{\mathbf{Q}} & \hat{\mathbf{Q}} \hat{\mathbf{B}} & \hat{\mathbf{C}}^{\mathrm{T}} \\
\hat{\mathbf{B}}^{\mathrm{T}} \hat{\mathbf{Q}} & -\gamma_{\mathbf{c}} \mathbf{I} & \mathbf{0} \\
\hat{\mathbf{C}} & \mathbf{0} & -\gamma_{\mathbf{c}} \mathbf{I}
\end{array}\right]<\mathbf{0}
$$

Where matrix $\hat{\mathbf{Q}}$ is a symmetric positive definite matrix satisfying condition, $\hat{\mathbf{Q}}>0$. The feasibility of the matrix inequality of (11) results into optimizing control effort, disturbance attenuation and making controller less sensitive to model uncertainties [16]. Second controller objective of ensuring minimum specified damping in system requires confining closed loop system poles inside the conic region (internal angle $\theta_{i}$ ) in s-plane. The second objective leads to the $2^{\text {nd }}$ matrix inequality condition to be satisfied in design of controller and is given in (12), [26].

$$
\left[\begin{array}{ll}
\sin \theta_{i}\left(\hat{\mathbf{Q}} \hat{\mathbf{A}}+\hat{\mathbf{A}}^{\mathrm{T}} \hat{\mathbf{Q}}\right) & \cos \theta_{i}\left(\hat{\mathbf{Q}} \hat{\mathbf{A}}-\hat{\mathbf{A}}^{\mathrm{T}} \hat{\mathbf{Q}}\right) \\
\cos \theta_{i}\left(\hat{\mathbf{A}}^{\mathbf{T}} \hat{\mathbf{Q}}-\hat{\mathbf{Q}} \hat{\mathbf{A}}\right) & \sin \theta_{i}\left(\hat{\mathbf{Q}} \hat{\mathbf{A}}+\hat{\mathbf{A}}^{\mathrm{T}} \hat{\mathbf{Q}}\right)
\end{array}\right]<\mathbf{0}
$$

The matrix inequalities as stated in (11) and (12) are bilinear matrix inequalities(product of unknown matrices in single term) and are converted into linear matrix inequalities (LMIs) by method of substitution of matrix variables,
$[16,25,26]$.The two matrix inequalities stated under (11) and (12) act as constraint of an optimization problem. The objective function of which is minimization of scalar $\gamma_{c}\left(\right.$ for $\left.\gamma_{c}>0\right)$. The solution to the resultant optimization problem gives controller state matrices $\left(\mathbf{A}_{\mathbf{c}}, \mathbf{B}_{\mathbf{c}}, \mathbf{C}_{\mathbf{c}}\right)$ along with the matrix $\hat{\mathbf{Q}}[25,26]$.

\section{Proposed FTC design of self contained actuators unit:}

In this section the concept of self contained actuators unit as actuator fault-tolerant control design is discussed. In wide area control and damping of power system first a robust wide area damping controller(WRDC) with multiple outputs connected to multiple actuators is designed. The group of actuators involved in damping of oscillations in wide area control act as a self independent unit for different operating conditions of nominal system as well as for system with actuator faults. The unit is even effective for damping of power oscillations even when one or more actuators goes off and the number of active actuators is reduced. Reconfigurable control is added to the design of WRDC where a reconfiguration component(RC) is embedded in the feedback path of the controller. RC is designed along the lines of fault hiding principle and is activated only on occurrence of actuator fault. On activation $\mathrm{RC}$ connects to remaining active actuators and together make-up for loss of control action due to actuator faults. RC redistributes control effort among the active actuators to meet system performance objectives.Hence no redundant actuator is required post actuator fault to transfer control to prevent system performance from deteriorating. The multiple actuators involved in WAC of power system under reconfigurable control acts as one self contained unit capable to keep system response unaffected from any actuator faults. With fault hiding principle based reconfigurable control the $\mathrm{RC}$ acts as virtual actuator on occurrence of actuator fault. Under the proposed fault tolerant control design nominal wide area damping controller(WRDC) can be used without any changes to its parameter. The design of reconfiguration component that leads to self contained actuators unit is discussed below.

The schematic diagram illustrating working of reconfigurable control for fault tolerant WAC involving multiple actuators is shown in Fig. 2. $A_{1}, A_{2}, \ldots, A_{n}$ are the $\mathrm{n}$ number of wide area control actuators connected to $\mathrm{n}$ outputs of wide area controller. The reconfigurable control on actuator fault introduces a new dynamical block called reconfiguration component(RC) in the feedback loop. The design of $\mathrm{RC}$ is along the lines of fault hiding principle(fhp). On activation of $\mathrm{RC}$ the input to controller(WRDC) in the Fig. 2 is the reconfigured system output $\left(\mathbf{y}_{\mathbf{c}}\right)$ and output from controller is the new reconfigured signal $\left(\mathbf{u}_{\mathbf{c}}\right)$. While the actual input and output signals of power system on account of actuator fault are 


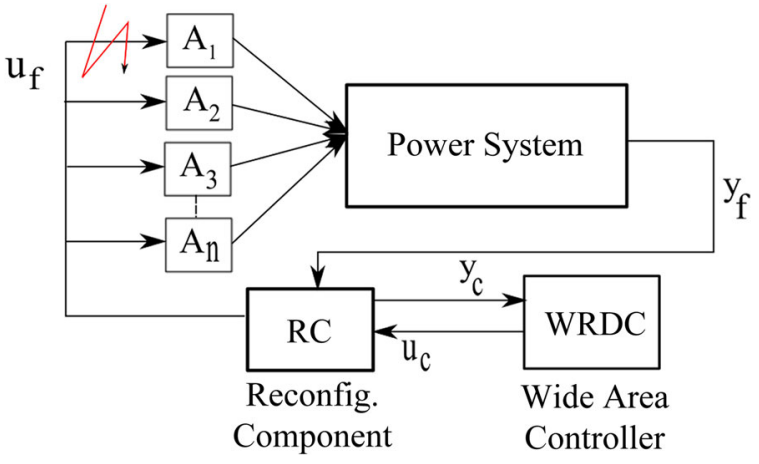

Fig. 2 Schematic diagram of wide area damping control

$\mathbf{u}_{\mathbf{f}}$ and $\mathbf{y}_{\mathbf{f}}$ respectively. The main objective of $\mathrm{RC}$ is to hide actuator fault from the controller and stabilize the system output. The dynamic equation describing the internal dynamics of the RC is given in (13).

$$
\Sigma_{G_{R} e}:\left\{\begin{array}{c}
\dot{\tilde{\mathbf{x}}}=\mathbf{A} \tilde{\mathbf{x}}-\mathbf{B}_{\mathbf{f}_{\mathbf{i}} \mathbf{u}_{\mathbf{f}}+\mathbf{B} \mathbf{u}_{\mathbf{c}}} \\
\mathbf{u}_{\mathbf{f}}=\mathbf{M}_{\mathbf{i}} \tilde{\mathbf{x}}+\mathbf{N}_{\mathbf{i}} \mathbf{u}_{\mathbf{c}} \\
\mathbf{y}_{\mathbf{c}}=\mathbf{y}_{\mathbf{f}}+\mathbf{C} \tilde{\mathbf{x}}
\end{array}\right.
$$

Matrix $\mathbf{B}_{\mathbf{f}_{\mathrm{i}}}$ represents $i^{i \text { th }}$ actuator fault and its $i^{\text {th }}$ column corresponding to $i^{\text {th }}$ actuator is scaled by $\alpha,(\alpha \geq 0)$ and elements of $i^{\text {th }}$ column given by $\alpha b_{j i}, j=1,2, . . n$. Further (13) is reduced to (14).

$$
\begin{array}{r}
\dot{\tilde{\mathbf{x}}}=\mathbf{A}_{\Delta} \tilde{\mathbf{x}}+\mathbf{B}_{\Delta} \mathbf{u}_{\mathbf{c}} \\
\mathbf{y}_{\mathbf{c}}=\mathbf{y}_{\mathbf{f}}+\mathbf{C} \tilde{\mathbf{x}} \\
\text { where } \mathbf{A}_{\Delta}=\mathbf{A}-\mathbf{B}_{\mathbf{f}_{\mathbf{i}}} \mathbf{M}_{\mathbf{i}} \\
\mathbf{B}_{\Delta}=\mathbf{B}-\mathbf{B}_{\mathbf{f}_{\mathbf{i}}} \mathbf{N}_{\mathbf{i}}
\end{array}
$$

The feedback gain matrix $\mathbf{M}_{\mathbf{i}}$ of $\mathrm{RC}$ for (14) is determined such that eigenvalues of matrix $\left(\mathbf{A}-\mathbf{B}_{\mathbf{f}_{\mathbf{i}}} \mathbf{M}_{\mathbf{i}}\right)$ have negative real parts. Using pole placement design large negative eigenvalues can be chosen. Since in (13) state vector $(\tilde{x})$ represents deviation in state trajectory from nominal state path on actuator fault, choosing large negative eigenvalues will lead to fast disappearance of deviation in state of reconfigured system. The parameter $M_{i}$ of RC corresponding to fault of $i^{\text {th }}$ actuator in multiple actuator led WAC is dependent on remaining active actuators(non zero columns of $\mathbf{B}_{\mathbf{f}_{\mathbf{i}}}$ ). The dependence of RC on input matrix $\mathbf{B}_{\mathbf{f}}$ to meet desired eigenvalues of (14), results into new and distinct parameter matrix $\mathbf{M}$ for each actuator fault. This in turn decides the redistribution of wide area control input by RC among remaining active actuators. In nominal system condition the distribution of wide area control signal among the actuators is based on control law of (7). In case of actuator fault the distribution of wide area signal input among the remaining active actuators is based on (14).
A new state vector $(e)$ giving deviation in state trajectory of faulty system from nominal system is introduced. Where $\mathbf{e}=\mathbf{x}_{\mathbf{f}}+\tilde{\mathbf{x}}$ modifies the state variable model as given in (15). The new state vector $e$, can be interpreted as the state of nominal system.

$$
\begin{array}{r}
\left(\begin{array}{c}
\dot{\mathbf{e}} \\
\dot{\tilde{\mathbf{x}}}
\end{array}\right)=\left(\begin{array}{cc}
\mathbf{A} & \mathbf{0} \\
\mathbf{0} & \mathbf{A}-\mathbf{B}_{\mathbf{f}_{\mathbf{i}}} \mathbf{M}
\end{array}\right)\left(\begin{array}{c}
\mathbf{e} \\
\tilde{\mathbf{x}}
\end{array}\right)+\left(\begin{array}{c}
\mathbf{B} \\
\mathbf{B}-\mathbf{B}_{\mathbf{f}_{\mathbf{i}}} \mathbf{N}
\end{array}\right) \mathbf{u}_{\mathbf{c}} \\
\mathbf{y}_{\mathbf{c}}=\left(\begin{array}{lll}
\mathbf{C} & \mathbf{O}
\end{array}\right)\left(\begin{array}{l}
\mathbf{e} \\
\tilde{\mathbf{x}}
\end{array}\right)
\end{array}
$$

The reconfigured signals $\mathbf{u}_{\mathbf{c}}$ and $\mathbf{y}_{\mathbf{c}}$ in (15) are the output and input signals of controller(WRDC). As seen from (15) the reconfigured system dynamics(e) presented to WRDC $\left(\mathbf{u}_{\mathbf{c}}\right.$ and $\left.\mathbf{y}_{\mathbf{c}}\right)$ is such that no actuator fault has taken place. Inserting RC between WRDC and power system hides actuator fault from WRDC.

The parameters of $\mathrm{RC}$ are dependent on actuator fault. The relationship between the parameters $\left(M_{i}, N_{i}\right)$ of RC and active actuators remaining in the wide area unit of actuators $\left(\left\{\mathbf{A}_{\mathbf{1}}, \mathbf{A}_{2}, \ldots, \mathbf{A}_{\mathbf{N}}\right\}\right)$ on any $i^{\text {th }}$ actuator fault is given by (17). The $i^{\text {th }}$ actuator fault is represented by input matrix $\mathbf{B}_{\mathbf{f}_{\mathbf{i}}}$ (with all zeros $i^{\text {th }}$ column).

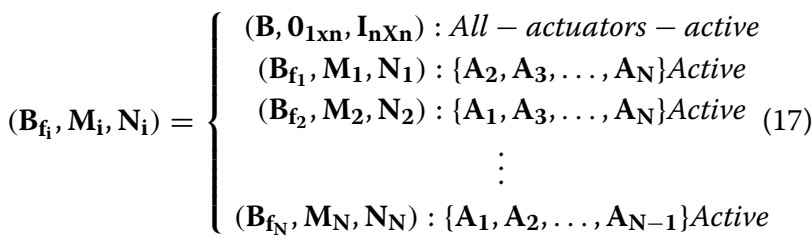

This results in parameters of $\mathrm{RC}$ becoming dynamic with respect to actuator fault and change with respect to change in actuator fault as given in (17). For each actuator fault RC assumes related parameters from (17) and drives remaining active actuators to stabilize the system output. The control effort is redistributed by RC among active actuators to keep system response unaffected by actuator fault. More details on state variable model of reconfigured system and design of reconfiguration components can be found in $[27,28]$ and $[29]$.

\section{Numerical Results And Discussion}

\subsection{Case Study}

One of the bench mark model for study of stability methods in power system, Kundur's 2-Area Power System [20], is used here in testing and demonstrating efficacy of proposed method. [20] is used in several methods as in $[6,15]$ to demonstrate respective robust controllers in damping of low frequency power oscillations in power system . [20] comprises of 4 generating machines, set of tie lines connecting two areas Area-1 and Area-2. In the modified model a HVDC line is introduced between the two areas Area- 1 and Area- 2 for transmission of power between the regions. The line diagram of two area power system is shown in Fig. 3. A Static VAR compensator 


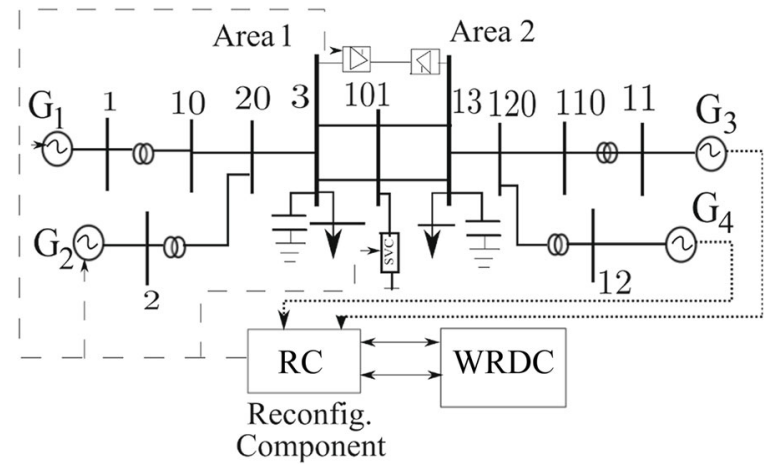

Fig. 3 Two-Area Power System with WAC: Dotted lines show remote feedback connections \& dashed lines show wide area control input

(SVC) is configured in power system and installed at bus in the centre of tie-lines. The system parameters and related details are mentioned in [20,30]. Each generator is represented by a sub-transient model and is of $5^{\text {th }}$ order with two damper windings and rated at 1000 MVA. A IEEE type-1A D.C excitation system ( $3^{\text {rd }}$ order $)$, TG model( $3^{\text {rd }}$ order $)$, Power system stabilizer(PSS)( $3^{\text {rd }}$ order $)$ at generator input for damping of local modes. SVC rated at $200 \mathrm{MVA}\left(2^{\text {nd }}\right.$ order $), \mathrm{HVDC}$ line transporting power at $510 \mathrm{kV}\left(1^{\text {st }}\right.$ order $)$.

\subsection{Modal Analysis}

The operating point considered is for an inter-area power transfer of $300 \mathrm{MW}$ from Area-1 to Area-2. The small signal model of the power system at the nominal operating point is of order 65, obtained using Matlab toolbox PST [31]. In absence of WRDC system model is treated as open loop system in context of wide area control(WAC). The two critical eigen modes with insufficient damping are listed in Table 1.

Mode $l_{1}$ in Table 1 is inter-area mode where machines $G_{1}, G_{2}$ from Area-1 oscillates against $G_{3}, G_{4}$ from Area2 [32]. Mode $l_{2}$ in Table 1 is an intra-area mode where machines from same area oscillate against each other. A wide area control scheme utilizing relevant system output as feedback signals (y) connected to WRDC and output from WRDC connected to suitable inputs of power system as wide area control $\operatorname{signal}(\mathbf{u})$ is implemented. Machines $G_{1}, G_{2}, H V D C$ system and SVC are selected as inputs for control signal(u) coming from wide area controller. While signals $p e_{3} a n d p e_{4}$ giving power generation at machines $G_{3}$ and $G_{4}$ are selected as feedback signals(y)

Table 1 Critical mode

\begin{tabular}{lll}
\hline Mode type & $\operatorname{Damp}(\zeta)$ & Freq $(\mathrm{Hz})$ \\
\hline Inter-area $\left(/_{1}\right)$ & 0.030 & 0.65 \\
Intra-Area $\left(/_{2}\right)$ & 0.046 & 0.97
\end{tabular}

and connected to controller thereby completing closed loop system in context of wide area control. The method of residues is used in selecting $p e_{3} \& p e_{4}$ as output feedback signals of power system connecting it to WRDC [33]. Residue values are considered as index of observability and controllability of the modes of oscillations [34, 35]. The highest controllability of modes $l_{1} a n d l_{2}$ is with WRDC connected to machine $G_{2}$.

Rotor speed $\left(\omega_{3}\right)$ of generator $\left(G_{3}\right)$ is chosen as performance signal. The eigen vectors corresponding to modes $\left(l_{1} a n d l_{2}\right)$ has $\omega_{3}$ as their largest component. This gives high observability of modes $l_{1} a n d l_{2}$ in rotor speed $\omega_{3}$. The actuator and sensor placements in WAC of power system $(G)$ is as given in Table 2 . The output of WRDC $(\mathbf{u})$ is fed to supplementary damping control inputs of $(i)$ excitation system of $G_{1}$ (ii) excitation system of $G_{2}$ (iii) HVDC system \& (iv) SVC. A detailed scheme of implementation of WAC in two area power system model is shown in Fig. 3. Where dash-lines represent wide area control signal $(\mathbf{u})$ to four selected actuators, and dotted lines represent system output feedback signal(y) as input to WRDC.

\subsection{Realization of WRDC: Nominal System Condition}

The connection of WRDC and power system is as shown by the inter-connection between controller $(\mathrm{K})$ and system $(\mathrm{G})$ shown in Fig. 1. This requires WRDC controller of same order as of power system model. A bulky model of WRDC is practically not viable hence power system model is reduced from it's original order $\left(65^{\text {th }}\right)$ to $8^{\text {th }}$ order. Balanced model order reduction techniques are used to preserve the frequency response of the original system into reduced order system model [36]. As per the design criterion laid down for wide area controller(WRDC), in Section 3, minimum damping specified for closed loop power system(PS with WRDC) is $\zeta_{\text {min }}=0.1$. WRDC with four outputs is tested to meet the multiple design objectives from control effort optimization, disturbance attenuation to ensuring minimum damping specified in system. The four actuators selected for connecting to multiple output WRDC are in the following order (i) $G_{1}$ as actuator for single output controller, (ii) $G_{1}, G_{2}$ as actuators for two output WRDC, (iii) $G_{1}, G_{2}$ and SVC for WRDC with three outputs, to (iv) $G_{1}, G_{2}$, SVC and HVDC system for four output WRDC. The location of multiple

Table 2 Actuator and sensor locations

\begin{tabular}{clc}
\hline$i$ & $A_{i}$ & $S_{i}$ \\
1 & $G_{1}$ & $P_{e 3}$ \\
2 & $G_{2}$ & $P_{e 4}$ \\
3 & HVDC & - \\
4 & SVC & -
\end{tabular}



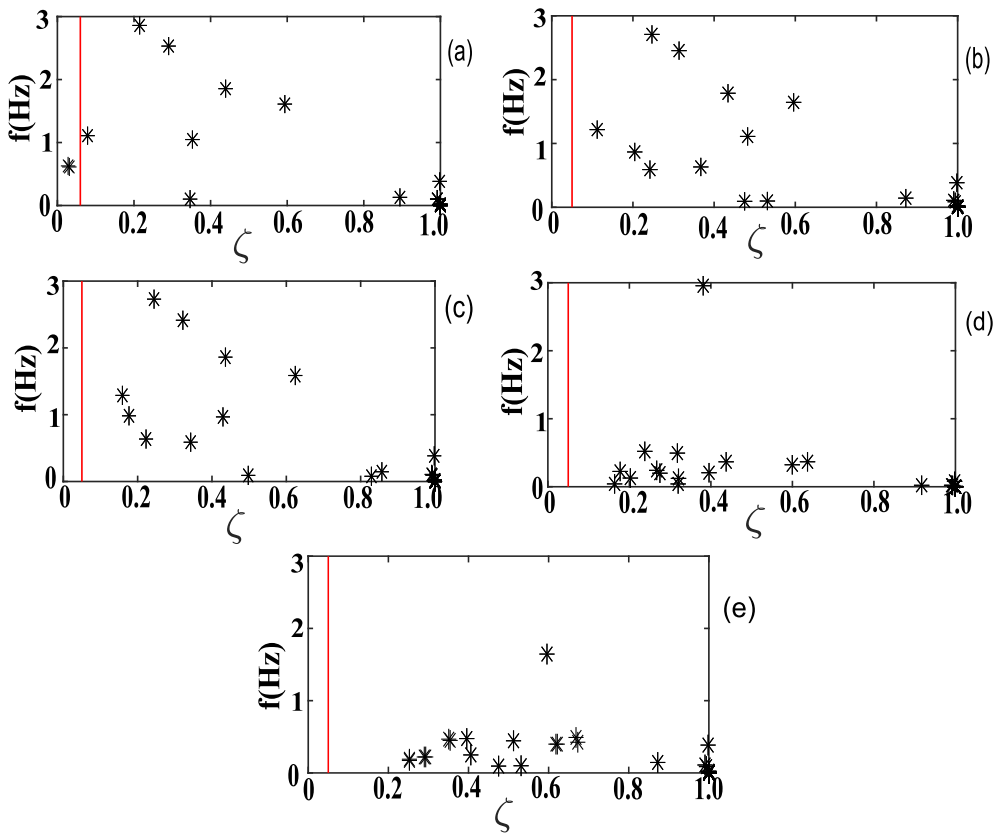

Fig. 4 Plot of eigen modes:(a) Open loop system (b) Single output WRDC; (c) WRDC with two outputs; (d) Three output WRDC; (e) Four output WRDC

actuators and feedback signals used in tuning of WRDC are listed in Table 2 \& shown in Fig. 3.

Plot of eigen modes involving damping $(\zeta)$ vs frequency(f) for WRDC with single, two, three and four outputs is given in Fig. 4. It can be seen from Fig. 4 system damping is highest corresponding to WRDC with four outputs. Table 3 gives critical mode $\left(\zeta_{\min }\right.$ and freq.) of closed loop system with WRDC having single output, two outputs, three outputs and four outputs. Figure 4 shows damping in system increases with increase in number of outputs of wide area controller. The damping achieved in system is largest in case of WRDC with four outputs $\left(\zeta_{\min }=0.22\right)$ double of specified damping $\left(\zeta_{\text {spe }}=\right.$ 0.1 ) in design objective. This establishes effectiveness of having multiple output controller over single output controller. The state space model of $\operatorname{WRDC}\left(\mathbf{A}_{\mathbf{c}}, \mathbf{B}_{\mathbf{c}} \& \mathbf{C}_{\mathbf{c}}\right)$ is given in Appendix A.

In Fig. 5 closed loop power system with WRDC in feedback(four output controller) is compared against open loop system, for different operating conditions in terms of the chosen dynamic response $\left(\mathbf{y}_{\mathbf{z}}\right)$ i.e change in speed of generator $G_{3}(\Delta \omega)$. The different operating points considered vary from system under single tie line(on outage of other tie-line) to change in power flow across tie-lines

Table 3 Critical modes of closed loop power system for different number wide area control inputs(outputs of WRDC)

\begin{tabular}{lllll}
\hline $\mathrm{O} / \mathrm{L}$ & $1 \mathrm{l} / \mathrm{P}$ & $2 \mathrm{l} / \mathrm{P}$ & $3 \mathrm{l} / \mathrm{P}$ & $4 \mathrm{l} / \mathrm{P}$ \\
$\zeta=.03$ & $\zeta=.1$ & $\zeta=.16$ & $\zeta=.19$ & $\zeta=0.22$ \\
$\mathrm{f}=.65(\mathrm{~Hz})$ & $\mathrm{f}=1.2(\mathrm{~Hz})$ & $\mathrm{f}=1.3(\mathrm{~Hz})$ & $\mathrm{f}=.03(\mathrm{~Hz})$ & $\mathrm{f}=0.03(\mathrm{~Hz})$ \\
\hline
\end{tabular}

for change in loads in the two area power system model. For every operating point considered closed loop(CL) system response under WRDC shows improved damping of oscillations compared to open loop(OL) system response.

\subsection{Actuator Fault(s)}

This part of the section demonstrates working of self contained actuators unit in restoring system performance in event of actuator faults taking place in wide area control of power system. The reconfigurable control on actuator fault restructures feedback loop such that WAC driven by multiple actuators makes for an self contained actuators unit capable of restoring system performance without depending on any redundant actuator outside the unit. The reconfiguration component(RC) embedded in the feedback loop gets activated on actuator fault and redistributes the wide area control input from WRDC among the remaining active actuators of the unit. The design implementation of reconfigurable control shows onlineactivation of reconfiguration component(RC) on actuator fault. This results in two reconfigured signals $\left(\mathbf{y}_{\mathbf{c}} \& \mathbf{u}_{\mathbf{c}}\right)$ at input and output of WRDC, hiding actuator fault from it. In design implementation along with reconfigured signals shown are actual output and input signals of power system $\left(\mathbf{y}_{\mathbf{f}} \& \mathbf{u}_{\mathbf{f}}\right)$ respectively. The redistribution of control signal by $\mathrm{RC}$ on actuator fault to remaining active actuators is seen in actual input $\operatorname{signal}\left(\mathbf{u}_{\mathbf{f}}\right)$. The distribution of control input among the actuators unit is dynamic and changes based upon actuator faults. The parameters of $R C$ corresponding to a actuator fault are determined online and control reconfiguration happens in real time. 


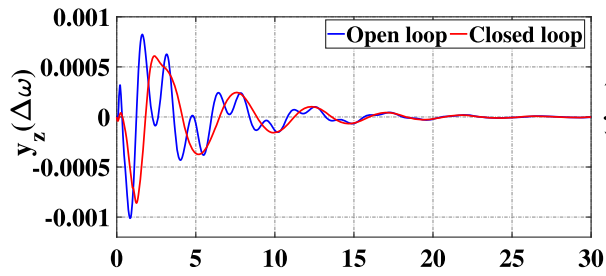

(a)

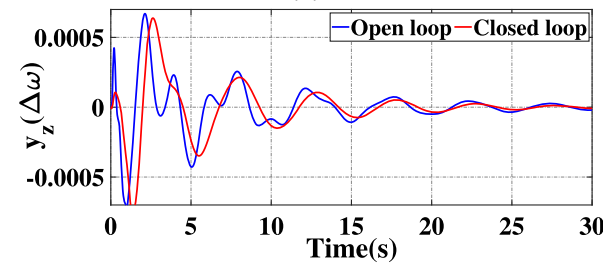

(c)

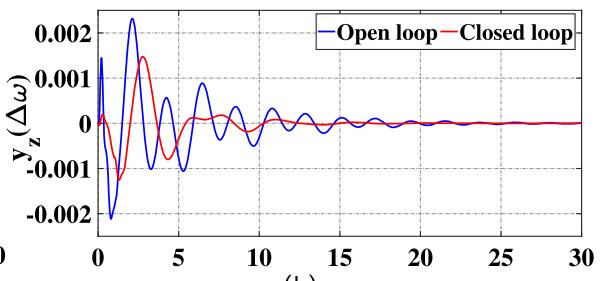

(b)

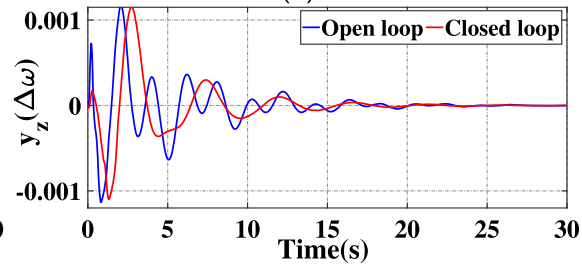

(d)

Fig. 5 Dynamic response of system with WRDC $(C L)$ versus without WRDC $(O L)$ under different operating conditions. a At nominal operating point(Tie-line power flow of 400MW) (b) Under one of the tie-line outage (c) Tie-line power flow of 700MW (d) Tie-line power flow of $100 \mathrm{MW}$

This makes for an autonomous fault tolerant control system and nominal controller(WRDC) along with RC makes for an fault tolerant wide area damping controller.

A disturbance is created in power system by outage of one of the two tie-lines for $1 \mathrm{~ms}$ and system response $\left(\mathbf{y}_{\mathbf{z}}\right)$ i.e change in speed of generator $G_{3}(\Delta \omega)$ is studied. A fault on actuator $A_{1}\left(G_{1}\right)$ is simulated at $t=4 \mathrm{~s}$. The online control reconfiguration caused by activation of $\mathrm{RC}$ together with remaining active actuators $\left\{A_{2}, A_{3}\right.$ and $\left.A_{4}\right\}$ result in reconfigured signals $\mathbf{u}_{\mathbf{c}}$ and $\mathbf{y}_{\mathbf{c}}$ at output and input of nominal controller as shown in Fig. 6. The Fig. 6a shows actual input signal $\mathbf{u}_{\mathbf{f}}$ to the system, where input line corresponding to actuator $A_{1}$ (in color blue) goes to zero for $t \geq 4 \mathrm{~s}$ indicating actuator fault. This causes activation of $\mathrm{RC}$ in system resulting in reconfiguration of system dynamics. The redistribution of control signals at $\mathrm{t}=4 \mathrm{~s}$ to remaining active actuators $A_{2}, A_{3}$ and $A_{4}$ can be clearly seen in signal $\mathbf{u}_{\mathbf{f}}$. In Fig. $6 \mathrm{~b}$ the reconfigured control signal $\left(\mathbf{u}_{\mathbf{c}}\right)$ as seen by controller WRDC at system input is shown. In $\mathbf{u}_{\mathbf{c}}$, WRDC sees all actuators up and active for all the time, no redistribution of control signals and hence sees no actuator fault. The signal $\mathbf{y}_{\mathbf{f}}$ shown in Fig. 6c is actual output signal of power system that goes as feedback to WRDC. The effect of integration of $\mathrm{RC}$ at $t=4 \mathrm{~s}$ causing sudden reconfiguration of system dynamics can be seen in form of spike at $t=4 \mathrm{~s}$ in actual feedback signal $\mathbf{y}_{\mathbf{f}}$. Whereas the feedback signal reaching to $W R D C$ is reconfigured signal $\mathbf{y}_{\mathbf{c}}$ (output of $\mathrm{RC}+\mathbf{y}_{\mathbf{f}}$ ) shown in Fig.6d. In $y_{c}$ WRDC sees no such disturbance at it's input due to any actuator fault. The reconfigured

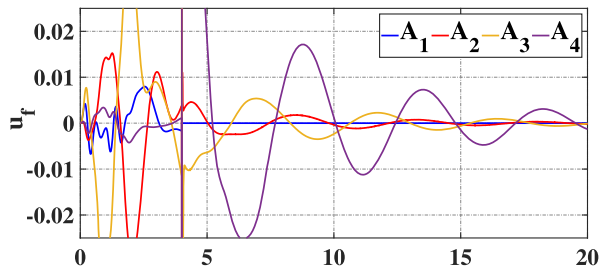

(a)

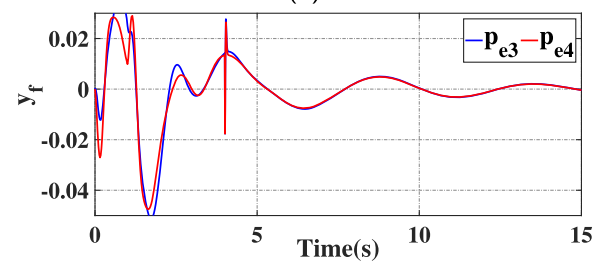

(c)

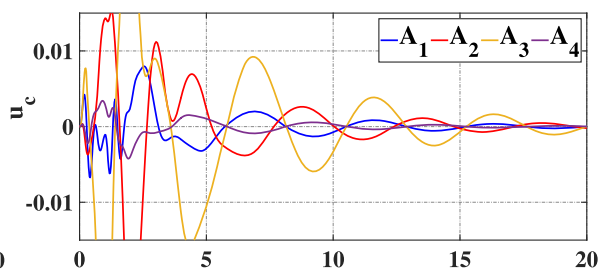

(b)

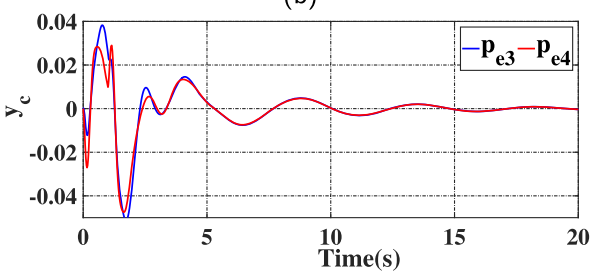

(d)

Fig. 6 System reconfiguration with actuators $\left\{A_{2}, A_{3}\right.$ and $\left.A_{4}\right\}$ active on actuator fault at $A_{1}$. a Actual input( $\left.\mathbf{u}_{\mathbf{f}}\right)$ to system; b Reconfigured control signal $\left(\mathbf{u}_{\mathbf{c}}\right)$ as seen by controller at system input; $\mathbf{c}$ Actual feedback signal( $\left.\mathbf{y}_{\mathbf{f}}\right)$ showing effect of integration of RC at time of fault; $\mathbf{d}$ Reconfigured feedback signal $\left(\mathbf{y}_{\mathbf{c}}\right)$ seen by controller at it's input 


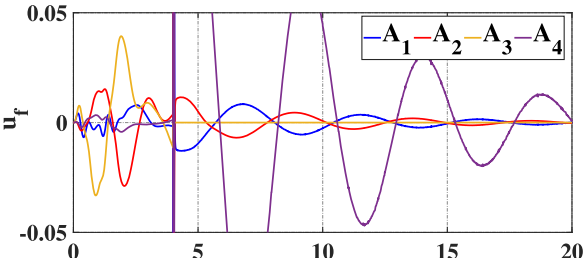

(a)

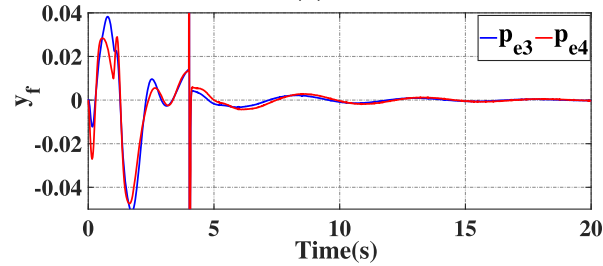

(c)

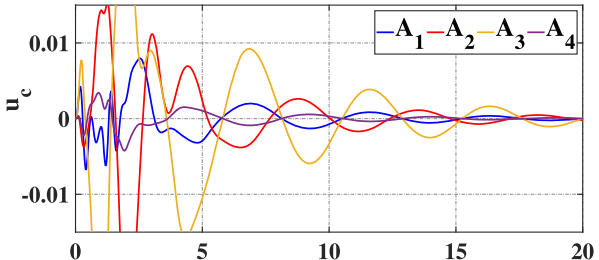

(b)

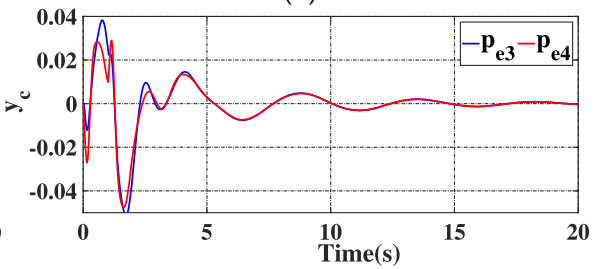

(d)

Fig. 7 System reconfiguration with actuators $\left\{A_{1}, A_{2}, A_{4}\right\}$ active on actuator fault at $A_{3}$. a Actual input $\left(\mathbf{u}_{\mathbf{f}}\right)$ to system; b Reconfigured control signal $\left(\mathbf{u}_{\mathbf{c}}\right)$ as seen by controller at system input; $\mathbf{c}$ Actual feedback signal $\left(\mathbf{y}_{\mathbf{f}}\right)$ showing effect of integration of RC at time of fault; $\mathbf{d}$ Reconfigured feedback signal( $\left.\mathbf{y}_{\mathbf{c}}\right)$ seen by controller at it's input

signals $\mathbf{y}_{\mathbf{c}}$ and $\mathbf{u}_{\mathbf{c}}$ thus successfully hides the fault at actuator $A_{1}$ from the $W R D C$, based on fault hiding principle. It aids in fast stabilizing the system response which otherwise is affected on actuator fault as shown in Fig. 8. The interfacing signals connecting WRDC to the reconfigured power system are $\mathbf{y}_{\mathbf{c}} \& \mathbf{u}_{\mathbf{c}}$. The parameter $\mathbf{M}_{\mathbf{1}}$ of $\mathrm{RC}$ to some arbitrary closed loop poles of reconfigurable block, on actuator fault at $A_{1}$ and corresponding to remaining active actuators $\left\{A_{2}, A_{3}, A_{4}\right\}$ is given in Appendix $\mathrm{B}$.

The Fig. 7 shows system reconfiguration on actuator fault at $A_{3}$ at $\mathrm{t}=4 \mathrm{~s}$ and control action completed with remaining active actuators $\left\{A_{1}, A_{2}, A_{4}\right\}$ from the unit of wide area actuators. The reconfigured signals $\left(\mathbf{y}_{\mathbf{c}}\right.$ and $\left.\mathbf{u}_{\mathbf{c}}\right)$ generated on fault at $A_{3}$, to actual input-output signals of system $\left(\mathbf{y}_{\mathbf{f}} a\right.$ and $\left.\mathbf{u}_{\mathbf{f}}\right)$ are shown in Fig. 7. The change in control signal $\left(\mathbf{u}_{\mathbf{f}}\right)$ at $t=4 \mathrm{~s}$, caused by activation of $\mathrm{RC}$ and redistribution among the remaining active actuators can be seen in Fig.7a. The reconfiguration of system dynamics on account of activation of $\mathrm{RC}$ at $\mathrm{t}=4 \mathrm{~s}$ and its effect on out put feedback signal $\mathbf{y}_{\mathbf{f}}$ is seen in Fig. 7c. While the two reconfigured signals $\left(\mathbf{y}_{\mathbf{c}}\right.$ and $\left.\mathbf{u}_{\mathbf{c}}\right)$ connecting WRDC to reconfigured system hides actuator fault at $A_{3}$ from it.The parameter $\mathbf{M}_{\mathbf{3}}$ of RC to some arbitrary closed loop poles of reconfigurable block, on actuator fault at $A_{3}$ and corresponding to active actuators set $\left\{A_{1}, A_{2}\right.$ and $\left.A_{4}\right\}$ is given in Appendix B.

Similarly faults at other actuators could be simulated and signals generated by system reconfiguration could be discussed. The reconfigurable control causes change in system dynamics by inserting new dynamical block(RC) between WRDC and power system. RC on activation causes reconfiguration of system dynamics allowing for stabilizing system response affected from actuator fault. The effects of actuator faults on chosen system performance path $\left(\mathbf{y}_{\mathbf{z}}\right)$ i.e rotor speed of generator $G_{3}$ are shown in Figs. 8 and 9. In Fig. 8a shows wide area control input to power system on actuator fault at $A_{1}$ at $\mathrm{t}=4 \mathrm{~s}$. The input line corresponding to actuator $A_{1}$ becomes zero for $t \geq 4 s$. It can be seen from Fig. 8a that in absence of RC there is no re-distribution of control input among other active actuators of the unit. The Fig. $8 \mathrm{~b}$ shows comparison of system performance path (Change in rotor speed of $G_{3}$ ) with and without $\mathrm{RC}$, on occurrence of actuator fault at $A_{1}$. While Fig. 9 compares effect

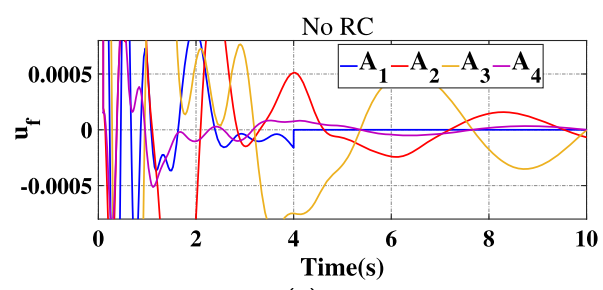

(a)

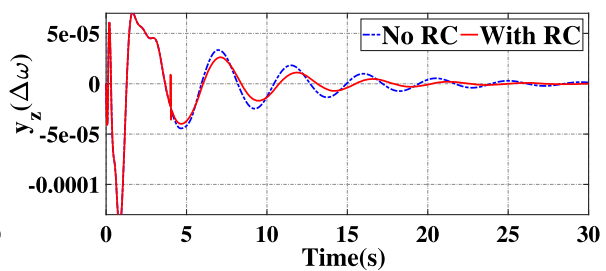

(b)

Fig. 8 Fault at actuator $A_{1}$ at $t=4 \mathrm{~s}$ : (a) Wide area control input to power system in absence of RC; (b) Comparison of system performance path (Change in rotor speed of $G_{3}$ ) with and without $R C$ 


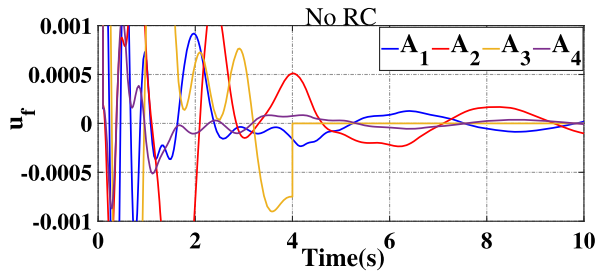

(a)

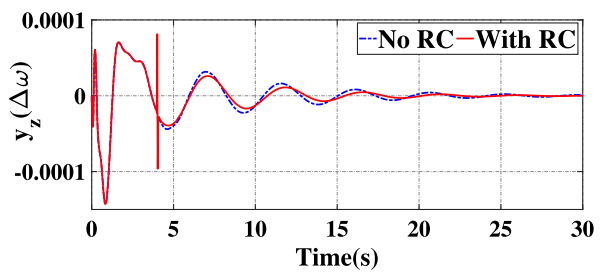

(b)

Fig. 9 Fault at actuator $A_{3}$ at $t=4 \mathrm{~s}$ : (a) Wide area control input to power system in absence of RC; (b) Comparison of system performance path (Change in rotor speed of $G_{3}$ ) with and without $R C$

of actuator fault at $A_{3}$ on system performance path $y_{z}$ with and without RC. In both the figures Figs. 8 and 9 it can be seen system response $\left(y_{z}\right)$ stabilizes fast in presence of RC compared to system response without RC. The actuators $\left(A_{1}, A_{2}, A_{3}, A_{4}\right)$ selected for wide area control action and tuned under reconfigurable control(following fault hiding principle), stabilizes system response in presence of actuator faults, without any need of redundant actuators thereby making for an self contained actuators unit.

Comparison of results from proposed method with other fault tolerant control methods on actuator and sensor faults in wide area control of power system is given in Table 4.

The results discussed from Figs. 6 and 7 clearly establishes group of actuators in WAC as self contained actuators unit not depending on any redundant actuators outside the unit, in case of actuator faults. While in [15] actuator fault severs feedback loop in WAC and requires control signal to be re-routed to redundant actuator. The use of multiple actuators in system as proposed here leads to higher damping compared to other two methods. Reconfigurable control(as proposed here) is activated only on occurrence of actuator fault unlike in [16] where designed controller is active even for nominal system condition and leads to conservative controller action in absence of fault.

\section{Conclusion}

A novel concept of self contained actuators unit in wide area control of damping in power system for nominal system condition under different operating points as well as for system affected by actuator faults is presented in the paper. A wide area robust damping controller is designed to meet multiple objectives from disturbance attenuation to ensuring minimum damping in system. Infinity norm minimization of closed loop transfer function and pole placement criterion is used in the design of wide area robust damping controller. The use of multiple output wide area controller feeding multiple actuators in power system allows for higher damping and fast settling of power oscillations in system. The wide area damping controller is tested for different operating conditions and controller is found suitable in providing sufficient damping in system compared to open loop system. The reconfigurable control design following fault hiding principle that is added to wide area controller is found to maintain sufficient system damping on actuator faults

Table 4 Comparison of results with other FTC methods in wide area control and damping of PS

\begin{tabular}{|c|c|c|c|c|c|c|}
\hline & & Fault & No. of & Minimum & Dependent & \\
\hline & & Tolerant & active & Damping & on & Switching \\
\hline \multirow[t]{4}{*}{ Paper } & \multirow[t]{3}{*}{ Fault } & Control & WAC & \multirow[t]{3}{*}{$\zeta_{\min }$} & redundant & of \\
\hline & & methodology & actuators / & & actuators / & $\mathrm{RC}$ \\
\hline & & & sensors & & sensors & \\
\hline & \multirow{3}{*}{ Actuator } & Dynamic & \multirow{3}{*}{ Multiple } & \multirow{3}{*}{$\begin{array}{l}\zeta_{\min }> \\
\zeta_{s p c}\end{array}$} & No (Self & \multirow{3}{*}{ Automatic } \\
\hline \multirow[t]{2}{*}{ Proposed } & & Reconfigurable & & & Contained & \\
\hline & & Control & & & Unit & \\
\hline \multirow{3}{*}{$\begin{array}{l}\text { Raoufat M.E. } \\
\text { [15] }\end{array}$} & \multirow{3}{*}{ Actuator } & Static & \multirow{3}{*}{$\begin{array}{l}\text { Single } \\
\text { actuator }\end{array}$} & \multirow{3}{*}{$\begin{array}{l}\zeta_{\min }= \\
\zeta_{s p c}\end{array}$} & \multirow{3}{*}{ Yes } & \multirow{3}{*}{ Manual } \\
\hline & & Reconfigurable & & & & \\
\hline & & Control & & & & \\
\hline \multirow{2}{*}{$\begin{array}{l}\text { Sevilla } \\
{[16]}\end{array}$} & \multirow{2}{*}{ Sensor } & \multirow{2}{*}{$\begin{array}{l}\text { Semi- } \\
\text { Active }\end{array}$} & \multirow{2}{*}{$\begin{array}{l}\text { Multiple } \\
\text { sensors }\end{array}$} & \multirow{2}{*}{$\begin{array}{l}\zeta_{\min }= \\
\zeta_{s p c}\end{array}$} & \multirow{2}{*}{ No } & Minimum \\
\hline & & & & & & Switching \\
\hline
\end{tabular}


taking place in system. The reconfiguration component is activated on actuator fault and together with remaining active actuators from the same group(earlier to actuator fault) stabilizes system response. The group of actuators involved in wide area control and damping act as an self sufficient actuators unit for maintaining system damping and preserving system response even in the case of actuator faults. The reconfiguration component is dynamic and assumes parameters that changes with respect to change in actuator fault but together with remaining active actuators act to maintain system damping level to pre-fault condition. On actuator fault wide area control signal is redistributed to the remaining active actuators by the reconfiguration component. A two area power system model is considered for implementing the proposed methods of designing (i) robust wide area damping controller and (ii) reconfiguration component to test their effectiveness in damping control. The results obtained show that reconfigurable control design for wide area damping controller having multiple outputs makes for an self contained actuators unit capable to maintain sufficient damping in system with or without actuator fault, under different operating points and independent of use of any redundant actuators.

\section{Appendix A}

$A_{c}=\left(\begin{array}{cccccccc}0.1710 & -1.7409 & 3.2733 & 1.6910 & 0.3461 & -4.8994 & -1.1374 & 7.2250 \\ 1.2781 & -1.3612 & 1.5381 & 0.0917 & -0.0372 & -4.5000 & -0.5359 & 4.4366 \\ -1.7444 & -2.1782 & -3.6012 & -8.1806 & 0.7019 & 2.4687 & 2.0896 & -2.7564 \\ -0.0557 & 0.7671 & 3.7192 & -0.3617 & -3.2694 & -0.8735 & 2.1639 & -2.2471 \\ 0.04264 & -0.5731 & 0.7163 & 5.3078 & -2.9143 & 2.0177 & 7.1287 & -6.7036 \\ 1.1957 & -0.7803 & 0.0736 & 0.4511 & -1.7304 & -3.2593 & -3.5096 & 4.5430 \\ -0.0961 & -0.4992 & -0.0162 & -1.7072 & 0.4617 & 1.5889 & -12.8076 & 24.1110 \\ 0.3499 & 0.1309 & -1.1687 & -3.8928 & -0.4294 & 1.5194 & -14.3748 & 0.8720\end{array}\right)$

$B_{c}=\left(\begin{array}{cccccccc}0.2391 & -0.4516 & -0.0098 & -1.4142 & 0.3205 & -1.4287 & 0.9617 & -0.9756 \\ 0.1014 & -0.2836 & -0.2957 & 1.0624 & 0.3243 & -0.9794 & 0.2547 & 0.9253\end{array}\right)^{T}$

$\mathbf{C}_{\mathbf{c}}=\left(\begin{array}{cccccccc}0.3680 & -0.0522 & 0.1192 & -0.0410 & -0.5885 & 0.2524 & 0.7456 & 1.1445 \\ 0.0423 & -0.2422 & -0.7053 & -0.6360 & 0.1930 & 0.4405 & 0.0217 & -1.5247 \\ 0.2223 & 0.7219 & 0.4906 & 1.3535 & 0.3904 & 1.6906 & -1.1098 & -0.8775 \\ -0.0077 & -0.0924 & -0.0642 & -0.0827 & -0.1096 & -0.2085 & 0.3493 & -0.1370\end{array}\right)$

\section{Appendix B}

$$
\begin{gathered}
M_{1}=1.0 e+05\left(\begin{array}{cccccccc}
0 & 0 & 0 & 0 & 0 & 0 & 0 & 0 \\
-0.1107 & 0.1545 & -0.2626 & 0.3001 & 0.2109 & 0.3395 & 0.0258 & -0.3972 \\
0.5803 & 0.1024 & 0.2879 & -1.6564 & -0.7673 & -1.2410 & -0.1535 & 1.6303 \\
-0.3682 & 0.1071 & -0.2590 & 0.7594 & 0.2735 & 0.6111 & 0.0556 & -0.7189
\end{array}\right) \\
M_{3}=1.0 e+05\left(\begin{array}{cccccccc}
0.1977 & -0.8128 & 1.0539 & -0.1729 & 0.0898 & -0.5675 & -0.0218 & 0.7393 \\
-0.1720 & 0.6105 & -0.6944 & -0.0690 & -0.0047 & 0.2157 & 0.0663 & -0.4616 \\
0 & 0 & 0 & 0 & 0 & 0 & 0 & 0 \\
-0.5829 & 2.1859 & -2.7574 & 0.4306 & -0.2983 & 1.4691 & 0.0267 & -1.7801
\end{array}\right)
\end{gathered}
$$

\section{Nomenclature}

$\delta$ rotor angle

$\omega, \omega_{0}$ rotor and synchronous speed

$\psi_{d}, \psi_{q} \quad \mathrm{~d}$-axis and q-axis flux linkages

$\psi_{f}, \psi_{k d}$ flux linkage to field coil and d-axis damper coil

$\psi_{k q 1}, \psi_{k d 2}$ flux linkages to two q-axis damper coils

$E_{f d}$ exciter output voltage

$i_{f}, i_{k d}$ current in field coil and d-axis damper coil

$i_{k q 1}, i_{k q 2}$ current in two q-axis damper coils

$K_{A}$ AVR gain constant

$K_{s}$ svc gain constant

$P_{s}^{H V D C}$ Supplementary control input of HVDC link

$P_{d c}$ HVDC link modified ordered power

$T_{A}$ AVR time constant

$T_{d_{0}^{\prime}}, T_{q_{0}^{\prime}}$ d-axis and q-axis open circuit transient time constants

$T_{d_{0}^{\prime \prime}}, T_{q_{0}^{\prime \prime}} \mathrm{d}$-axis and q-axis subtransient time constants

$T_{1 s}, \ldots T_{5 s}$ SVC time constants

$T_{d c}$ HVDC link time constant

$V_{\text {mod }}^{e}$ supplementary control input of Exciter

$V_{\text {mod }}^{s}$ supplementary control input of SVC

$V_{p s s}$ voltage output of PSS

$V_{\text {ref }}$ voltage reference set at input

$x_{d}, x_{q}$ and $x_{l}$ direct axis, quadrature axis and leakage reactance of generator

$x_{d}^{\prime}, x_{q}^{\prime} \quad \mathrm{d}$-axis and q-axis transient reactance of generator

$x_{d}^{\prime \prime}, x_{q}^{\prime \prime} \mathrm{d}$-axis and q-axis subtransient reactance of generator

$x_{a d u s}, x_{a q u s} \mathrm{~d}$-axis and q-axis mutual reactance of generator

$B_{s v c}$ net susceptance contributed by SVC

$\mathrm{H}, \mathrm{D}$ rotor Inertia and damping coefficient

$X_{1 s v c}, X_{2 s v c}$ SVC state variables

\section{Acknowledgments}

Not applicable.

\section{Authors' contributions}

First author DVN has studied the fault tolerant control methods in wide area control of power systems. DVN has formulated and implemented the control design of online fault tolerant control feature for wide area damping controller. MSRM has supervised and guided the work and under whom DV has done the above research work. Both authors read and approved the final manuscript.

Funding

No funding received from any agency.

\section{Availability of data and materials}

The Kundur's two-Area four generator power system model can be found in $[20,30]$. In [30] bench mark models for analysis and control of small signal oscillatory dynamics in power system are given.

\section{Competing interests}

The authors declare that they have no competing interests.

\section{Author details}

${ }^{1}$ Faculty of Science \& Technology, IFHE HYDERABAD, Shankerpally Road, 501203 Hyderabad, India. ${ }^{2}$ Dept. of EEE, CMR College of Engineering \& Technology, Medchal Road, 501401 Hyderabad, India. 
Received: 31 July 2019 Accepted: 2 January 2020

Published online: 05 February 2020

\section{References}

1. Prasertwong, K., Mithulananthan, N., Thakur, D (2010). Understanding lowfrequency oscillation in power system. International Journal of Electrical Engineering Education, 47(3), 248-262.

2. Korba, P., \& Larsson, M. (2012). Wide-area monitoring of electromechanical oscillations in large electric power systems, In IEEE Power Energy Social General Meeting. https://doi.org/10.1109/pesgm.2012.6344708. San Diego.

3. Rebello, E., Vanfretti, L., Almas, M. (2015). PMU-based real-time damping control system software and hardware architecture synthesis and evaluation, In IEEE Power Energy Social General Meeting. https://doi.org/10.1109/ pesgm.2015.7285812. Denver.

4. Supriyadi, C., Ngamroo, A.N.I., et al. (2011). GPS synchronized phasor measurement units-based wide area robust PSS parameters optimization. International Transactions on Electrical Energy Systems, 21(1), 345-362.

5. Shiri, F., \& Mohammadi-ivatloo, B (2015). Identification of inter-area oscillations using wavelet transform and phasor measurement unit data. International Transactions on Electrical Energy Systems, 25(11), 2831-2846.

6. Chaudhuri, B., Pal, B., Zolotas, A., Jaimoukha, I., Green, T.C. (2003). MixedSensitivity Approach to H-infinity control of power system oscillations employing multiple FACTS devices. IEEE Transactions Power Systems, 18(3), 1149-1156.

7. Deng, J., Li, C., Zhang, X. (2015). Coordinated design of multiple robust FACTS damping controllers: A BMI-based sequential approach with multimodel systems. IEEE Transactions Power Systems, 30(6), 3150-3159.

8. Singh, A.K., \& Pal, B.C. (2015). Decentralized Control of Oscillatory Dynamics in Power Systems using an Extended LQR. IEEE Transactions on Power Systems, 31, 1715-1728.

9. Jabr, R.A., Pal, B.C., Martins, N. (2010). A Sequential Conic Programming Approach for the Coordinated and Robust Design of Power System Stabilizers. IEEE Transactions on Power Systems, 25, 1627-1637.

10. Thangaiah, J.M., \& Parthasarathy, R. (2017). Delay-dependent stability analysis of power system considering communication delays. International Transactions on Electrical Energy Systems, 27(3), e2260.

11. Kaviarasana, B., Sakthivela, R., Kwonc, O.M. (2016). Robust fault tolerant control for power systems against mixed actuator failures. Non Linear Analysis: Hybrid Systems, 22, 249-261.

12. Zhang, S., \& Vittal, V. (2013). Design of wide area power system dampimng controllers resilient to communication failures. IEEE Transactions Power System, 28, 4292-4300.

13. Pedersen, A.S., Richter, J.H., Tabatabaeipour, M., Jóhannsson, H., Blanke, M. (2016). Fault tolerant emergency control to preserve power system stability. Control Engineering Practice, 53, 151-159.

14. Khosravania, S., Moghaddamb, I.N., Afsharc, A., Karraric, M. (2016). Widearea measurement based fault tolerant control of power system during sensor failure. Electric Power System Research, 137, 66-75.

15. Ehsan Raoufat, M., Tomsovic, K., Djouadi, S.M. (2016). Virtual Actuators for Wide-Area Damping Control of Power Systems. IEEE Transactions Power System, 31(6), 4703-4711.

16. Sevilla, F., Jaimoukha, I., Chaudhari, B., Korba, P. (2014). Fault tolerant control design to enhance damping of inter-area oscillations in power grids. International Journal Robust Nonlinear Control, 24(8-9), 1304-1316.

17. Zhang, Q., Zhang, X., Polycarpou, M.M., Parisini, T. (2014). Distributed sensor fault detection and isolation for multimachine power systems. International Journal Robust Nonlinear Control, 24, 1403-1430.

18. Zhang, Y., \& Bose, A. (2008). Design of wide-area damping controllers for interarea oscillations. IEEE Transactions Power System, 23, 1136-1143.

19. Yao, W., Jiang, L., Wen, J., Wu, Q.H., Cheng, S. (2014). Wide-area damping controller of FACTS devices for inter-area oscillations considering communication time delays. IEEE Transactions Power System, 29, 318-329.

20. Kundur, P. (1994). Power System Stability and Control. New York: McGrawHill.

21. Sauer, P.W., \& Pai, M.A. (1998). Power System Dynamics and Stability. New Jersey: Prentice Hall.

22. IEEE Committee Report (1981). Excitation System Models for Power System Stability Studies. IEEE Transactions of Power Apparatus and Systems, PAS-100, 494-509.

23. Larsen, E.V., \& Chow, J.H. (1987). SVC Control concepts for System Dynamic Performance, In IEEE Tutorial Course: Application of Static Var Systems for System Dynamic Performance, 87TH0187-5-PWR (pp. 36-53).
24. Simfukwe, D., Pal, B.C., Jabr, R.A., Martins, N. (2012). Robust and Low Order Design of FACTS and Power System Stabilizers for Oscillations Damping IET Generation Transmission and Distribution, 6, 445-452.

25. Chilali, M., \& Gahinet, P. (1993). H Design with Pole Placement Constraint: An LMI Approach. IEEE Transactions on Automatic Control, 41(3), 358-367.

26. Chilali, M., Gahinet, P., Apkarian, P. (1991). Robust pole placement in LMI regions. IEEE Transactions on Automatic Control, 44, 2257-2270.

27. Lunze, J., \& Steffen, T. (2004). Control reconfiguration by means of a virtual actuator, In Proceedings on IFAC Sympos on Fault Detection, Supervision and Safety for Technical Process. https://doi.org/10.1016/s1474-6670(17)364820 (pp. 131-136). Washington.

28. Richter, J.H. (2010). Reconfigurable Control of Nonlinear Dynamical Systems: A Fault-Hiding Approach, Ph.D. dissertation Institute of Automation and Computer Control (ATP). Bocham: Ruhr University.

29. Lunze, J., \& Steffen, T. (2006). Control reconfiguration after actuator failures using disturbance decoupling methods. IEEE Transactions on Automatic Control, 51(10), 1590-1601.

30. Canizares, C., Fernandes, T., Geraldi, E., et al. (2017). Benchmark Models for the Analysis and Control of Small-Signal Oscillatory Dynamics in Power Systems. IEEE Transactions on Power System, 32, 715-722.

31. Chow, J, \& Rogers, G (2016). Power System Toolbox Version 3.0. http:www. eps.ee.kth.se/personal/vanfretti/pst/Power_System_Toolbox_Webpage/ PST.html.

32. Xia, T., Zhang, Y., Chen, L., et al (2011). Phase angle-based power system inter-area oscillation detection and modal analysis. International Transactions on Electrical Energy Systems, 21(4), 1629-1639. Special Issue: Power System Measurement Data and their Applications.

33. Kunjumuhammed, L.P., Singh, R., Pal, B.C. (2012). Robust signal selection for damping of inter-area oscillations. IET Generation Transmission and Distribution, 6, 404-416.

34. Yuan, Y., Chen, L., Sun, Y., Li, G. (2008). Placement of SVCs and selection of stabilizing signals based on observability and controllability. IEEE Power Energy Soc. General Meeting, 1-7. https://doi.org/10.1109/pes.2008. 4596608.

35. Magaji, N., Mustafa, M., Muda, Z. (2010). Signals selection of SVC device for damping oscillation. International Conference Information Science, Signal Processing Application, 786-789. https://doi.org/10.1109/isspa.2010. 5605511.

36. Safonov, M., \& Chiang, R. (1989). A schur method for balanced truncation model reduction. IEEE Transactions on Automatic Control, 34(7), 729-733.

\section{Submit your manuscript to a SpringerOpen ${ }^{\circ}$ journal and benefit from:}

- Convenient online submission

- Rigorous peer review

- Open access: articles freely available online

- High visibility within the field

- Retaining the copyright to your article

Submit your next manuscript at $\gg$ springeropen.com 